\title{
MODELO DE DIMENSIONAMENTO DE CAMA DE AMORTECIMENTO PARA ROCHA ORNAMENTAL
}

\author{
Rafael Franco e Silva' \\ Marcio Luiz Siqueira Campos Barros ' \\ Suzi Kelly Pereira Franco ' \\ Alfredo César Vale de Araújo ' \\ Gustavo do Prado Siqueira'
}

\section{Resumo}

O estado do Espírito Santo é o principal produtor de rocha ornamental do país, sendo este setor responsável por $10 \%$ do seu PIB, apesar de sua importância o setor tem um baixo nível de automação e mecanização no segmento. Sendo assim muitos dos trabalhos realizado nas frentes de extração acontecem de forma empírica, com o objetivo de minimizar este problema, realizou-se um estudo, onde se aplicou as leis de newton, como a primeira lei que é a inercia, a segunda lei que nos diz que $\mathrm{Fr}=\mathrm{Mx}$ a, e a terceira lei que nos mostra que para cada ação existe uma reação de igual força mas sentido contrário. Com a aplicação deste conhecimento, criou-se um modelo de dimensionamento, onde as camas de amortecimento podem ser padronizadas, evitando a quebra do material no processo de tombamento das bancadas.

Palavras-chave: Rocha ornamental; Cama de amortecimento; Leis de Newton; Dimensionamento.

\section{CUSHION BED DESIGN MODEL FOR NATURAL ROCK}

\begin{abstract}
Espírito Santo state is the main producer of ornamental rock in the country, being this sector responsible for $10 \%$ of its PIB, despite all the importance of the sector we see a low level of automation and mechanization in the segment. So much of the work done on the extraction fronts happens empirically, to minimize this problem, we perform a study and apply Newton's laws, such as the first law that is inertia, the second law that tells us that $\mathrm{Fr}=\mathrm{M} \times \mathrm{a}$, and the third law that shows us that for every action there is a reaction of equal strength but opposite sense. With the application of these laws and some knowledge acquired during the study, it was possible to create a sizing model, able to standardize this type of work avoiding the breaking of the material in the process of overturning of the workbench.
\end{abstract}

Keywords: Natural rock; Cushion bed; Newton's Laws; Sizing.

\section{INTRODUÇÃO}

A extração de rochas ornamentais vem evoluindo com o passar dos séculos: apesar desta evolução as metodologias utilizadas no setor foram consolidadas com a prática, com um baixo embasamento técnico científico e, devido a isto, o aproveitamento do material de extraído vem obtendo uma recuperação baixa.

O Brasil produziu em 2017 mais de 9,2 milhões de toneladas de blocos de rocha ornamental. Levando-se em consideração que este valor representa apenas $25 \%$ de tudo que é extraído, observa-se o impacto ambiental causado, já que todo o rejeito fica depositado em forma de pilhas no local da extração. Assim, percebe-se a necessidade de mais estudo para aumentar a recuperação deste tipo de exploração [I].

O setor de rocha ornamental é de grande importância para as exportações nacionais, mas a explotação do mesmo ainda é realizada com um baixo nível de automação e eficiência. Para garantir a qualidade e maior eficácia, deve-se investir em pesquisa e inovação tecnológica, dando uma maior representatividade ao setor e fôlego para economia [I].

Assim, é de grande importância otimizar e registrar as melhores técnicas de exploração na área de rocha ornamental, consolidando e agregando conhecimento a esta setor, que

'Programa de Pós-graduação em Engenharia Mineral - PPGEMinas, Universidade Federal de Pernambuco - UFPE, Recife, PE, Brasil. E-mail: rafaelfrancosil@gmail.com

2176-1523 (C) 2019 Associação Brasileira de Metalurgia, Materiais e Mineração. Publicado pela ABM. Este é um artigo de acesso aberto distribuído sob os termos da licença Creative Commons CC BY-NC-ND (Attribution-NonCommercial-NoDerivs) - https:// creativecommons.org/licenses/by-nc-nd/4.0\%. 
pode se tornar mais competitivo com a utilização de novas técnicas e tecnologias.

O setor de rocha ornamental, apesar de sua relevância no cenário mundial (tanto para mineração ou para construção civil), ainda é muito frágil, pois ao visitarmos as frentes de extração, temos um trabalho muito mecanizado, tornando o setor dependente do fator humano, gerando um maior custo ao empresário, reduzindo sua lucratividade bem como a recuperação de material pétreo que por diversas vezes são perdidos no processo de extração.

A cama de amortecimento é confeccionada nas frentes de extração de rocha ornamental com material terroso ou utilizando a combinação desse material e restos de blocos, tendo as suas dimensões adaptadas aos parâmetros geométricos da bancada, tornando-a capaz de amortecer o tombamento da mesma como vemos na Figura I. Tendo a sua forma geométrica de base retangular, e sua vista lateral um triângulo retângulo [2].

O estado do Espírito Santo acha-se inserido no sistema orogênico da Mantiqueira, o qual constitui uma entidade geotectônica de idade Neoproterozóica estruturada na direção NNE - SSW, bordejando a porção leste do craton do São Francisco. Esta entidade é constituída por um cinturão de rochas metamórficas, dobradas, em parte migmatizadas, incluindo suítes granitóides de idades e natureza composicional diversas, comprovando a existência de eventos magmáticos distintos ao longo de sua evolução orogenética $[3,4]$.

Relacionados aos eventos datados do Neoproterozóico, tem-se como rochas mais antigas, os paragnaisses e os gnaisses movimentados de coloração amarelo dourada, os quais compõem o complexo Nova Venécia, constituídos por silimanita-granada-cordierita gnaisse bandados bem foliados, contendo intercalações calcissilicáticas, quartzíticas e anfibolíticas. São formados por níveis escuros apresentando biotita, cordierita e granada em alternância com leitos ricos em minerais félsicos de composição quartzo-feldspática. Nas zonas migmatizadas ocorrem transposição de estruturas estromáticas para núcleos mais homogêneos, diatexíticos [4].

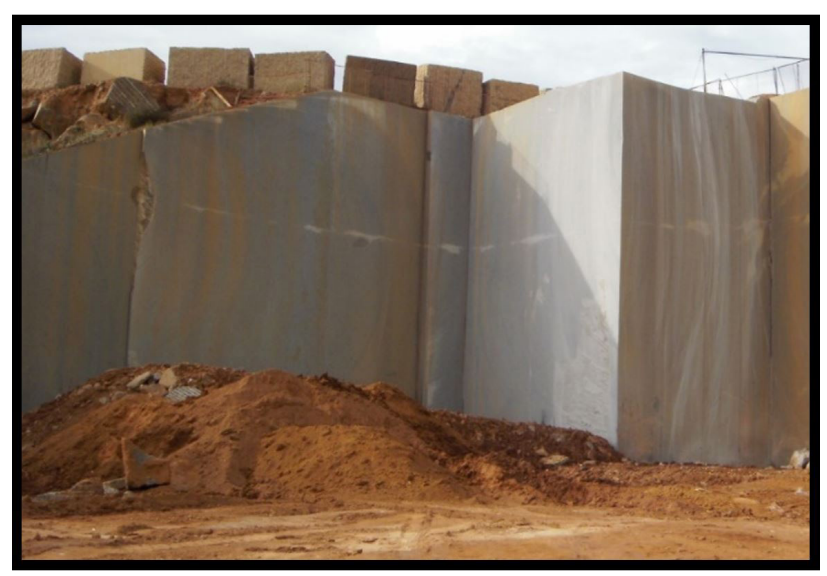

Figura I. Cama de amortecimento esperando para o tombamento do quadrote [2].

\section{METODOLOGIA}

Foi realizado um levantamento bibliográfico, onde se verificou uma quantidade significante de estudos no setor de rocha ornamental, principalmente no seu beneficiamento, mas dentre esses estudos poucos falam da cama de amortecimento, não tendo relevância no que se diz respeito ao dimensionamento da mesma.

A coleta de dados se deu em diversas frentes de extração de rocha ornamental no noroeste do Espírito Santo; com a utilização de uma trena de $20 \mathrm{~m}$, foi possível coletar as dimensões da base das bancadas ultra-altas, como largura e comprimento, bem como os valores das dimensões da cama de amortecimento, como largura, altura e comprimento.

Já para a coleta da altura das bancadas ultra-altas, foi utilizado uma corda com peso em uma de suas extremidades, onde um operador vai até o topo da bancada ultra-alta, iniciando a descida do conjunto corda-peso e quando o peso chega à base, marca-se o comprimento da corda. Transporta-se então a corda para um local apropriado e mede-se o comprimento da bancada.

Com o auxílio de revisão bibliográfica em outras áreas das ciências exatas e da Natureza, será desenvolvida uma nova metodologia para dimensionamento e confecção das camas de amortecimento visando seu tamanho adequado.

\section{RESULTADOS E DISCUSSÃO}

As camas de amortecimento são utilizadas na extração de rocha ornamental há muito tempo, pois a função destas é impedir que a bancada entre em contato direto com o piso, criando trincas e até quebrando-as ou trincando o material que se encontra no piso, prejudicando $o$ avanço do próximo nível.

A confecção das camas de amortecimento é realizada com material terroso (argila) e, até em alguns casos, quando seu volume é muito grande, restos de blocos que seriam jogados no bota-fora são misturados a este material terroso, para aumentar o volume da cama. Porém, esta técnica faz com que a cama diminua sua eficiência, já que os restos de blocos de rocha ornamental não se deformam como o material terroso, para absorver o impacto da queda da bancada.

Esta argila, que é utilizada para confecção das camas de amortecimento, em sua maioria, é utilizada como recuperação do material de descoberta do maciço rochoso, garantindo $o$ avanço da frente de extração. Entretanto, em alguns casos, este material não é suficiente para a confecção das camas, fazendo com que o empreendedor necessite de uma área de empréstimo. A utilização desta área faz com que se tenha um aumento no seu custo de operação, pois aumenta a despesa com a escavação e transporte deste material para frente de lavra, onde será confeccionada a cama de amortecimento. Além destes custos diretos, tem-se ainda - impacto ambiental gerado pela utilização desta área de empréstimo. Para sua utilização, é necessário o licenciamento ambiental e, posteriormente, a recuperação da área que foi degradada, gerando novos custos ao empreendimento. 
O modelo de cama utilizado hoje nas pedreiras de rochas ornamentais tem seu cálculo realizado de forma empírica, onde o volume da cama será o mesmo que o volume da bancada a qual se pretende tombar. Contudo, apesar de se conhecer o volume de material que será utilizado, ainda é necessário determinar suas dimensões. A proporção da cama de amortecimento é uma variável do tamanho da bancada que se pretende tombar, como por exemplo: uma bancada com altura de $54 \mathrm{~m}$, para a confecção de sua cama de amortecimento, deve-se ser acrescido $2 \mathrm{~m}$ em seu comprimento, ficando assim com $56 \mathrm{~m}$, desta forma é garantindo que a mesma, ao cair, se mantenha na cama.

Já a bancada possuindo seu comprimento de $38 \mathrm{~m}$, se deve acrescentar $1,5 \mathrm{~m}$ de cada lado na largura da cama de amortecimento. Assim, a cama terá uma largura de $4 \mathrm{Im}$, garantindo que ao tombar o material rochoso, o mesmo se mantenha na cama, como mostra a Figura 2.

Para achar a altura da cama e dimensionar o seu volume, se faz uso da Equação I, onde a cama de amortecimento tem a forma de um prisma retangular dividido ao meio em sua diagonal. Para realizar este cálculo, utilizaremos os valores que das bancadas que se encontra na Tabela $\mathrm{I}$.

$$
V=\frac{C x L x H c}{2}
$$

Onde:

$C=$ Comprimento da cama em metros;

$\mathrm{L}=$ Largura da cama em metros;

$\mathrm{Hc}=$ Altura da cama em metros.

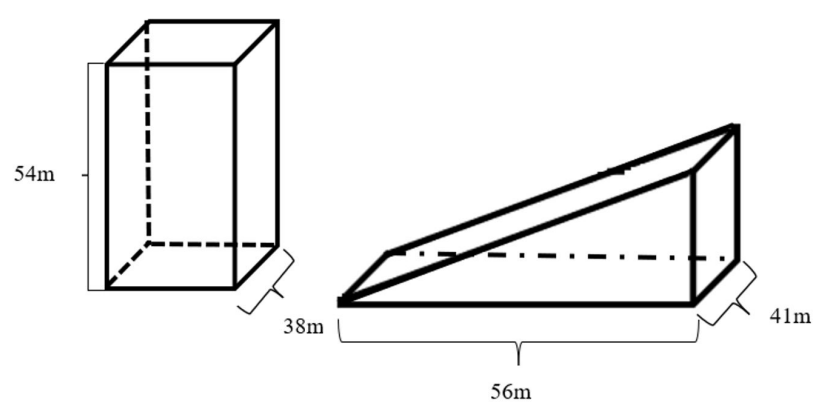

Figura 2. Dimensões da bancada ultra-alta e sua cama de amortecimento.
Como o objetivo é de encontrar o valor da altura da cama, nossa Equação I se modifica para uma Equação 2 a seguir. De posse dos valores para o comprimento e largura da cama, pudemos aplicar esta equação e verificar qual a altura empírica da mesma, na Tabela $\mathrm{I}$.

$$
H c=\frac{2 x V}{C x L}
$$

Onde:

$\mathrm{C}=$ Comprimento da cama em metros;

$\mathrm{L}=$ Largura da cama em metros;

$\mathrm{Hc}=$ Altura da cama em metros.

$\mathrm{V}=$ Volume da Cama em $\mathrm{m}^{3}$

Neste ponto, vamos precisar do conhecimento das leis de Newton para nos ajudar a dimensionar uma cama de amortecimento. A I ${ }^{\circ}$ Lei de Newton (equação da inércia), nos mostra que um corpo em movimento permanece em movimento quando a resultante das forças que atuam sobre ele é zero. Sendo assim, um corpo que está parado tende a continuar parado, a não ser que a resultante de suas forças seja diferente de zero [5].

Já na $2^{\circ}$ lei de Newton, vamos ter o comportamento dos corpos quando a resultante de suas forças for diferente de zero. Sendo possível explicar a relação entre as forças, massa e aceleração, como pode ser observado na Equação 3 [5].

$$
F r=M x a
$$

Onde:

$\mathrm{Fr}=$ força resultante $\mathrm{N}$;

$M=$ Massa em $\mathrm{Kg}$;

$a=$ aceleração em $\mathrm{m} / \mathrm{s}^{2}$.

A $3^{\circ}$ lei de Newton nos diz que, quando um objeto aplica uma força sobre um corpo, recebe a mesma força na mesma intensidade, só que em sentido contrário, como visto na Figura 3. Com isso, pode-se dizer que a força aplicada na cama pela bancada, deve ser a mesma força que a cama tem de realizar sobre a bancada durante o amortecimento [5].

Considerando a aceleração da gravidade igual a $10 \mathrm{~m} / \mathrm{s}^{2}$ e utilizando a Equação 3 . Encontramos os valores que a cama de amortecimento deve realizar sobre a banca que está sendo derrubada, para promover sua desaceleração e seu amortecimento. $\mathrm{Na}$ Tabela 2 observamos os valores das forças encontradas para cada bancada.

Tabela I. Demostração de todos os parâmetros que se deve levar em consideração para o cálculo da altura da cama de forma empírica

\begin{tabular}{ccccccccc}
\hline Bancada & $\mathbf{C}(\mathbf{m})$ & $\mathbf{L}(\mathbf{m})$ & $\mathbf{H}(\mathbf{m})$ & $\mathbf{V}\left(\mathbf{m}^{3}\right)$ & $\mathbf{M}(\mathbf{K g})$ & Cama & $\mathbf{C I}(\mathbf{m})$ & $\mathbf{L I}(\mathbf{m})$ \\
\hline$I$ & 38,00 & 12,00 & 54,00 & $24.624,00$ & $66.484,80$ & $\mathrm{I}$ & 56,00 & 41,00 \\
2 & 15,00 & 10,00 & 50,00 & $7.500,00$ & $20.250,00$ & 2 & 52,00 & 18,00 \\
3 & 23,60 & 6,00 & 27,00 & 3823,20 & $10.322,64$ & 3 & 29,00 & 26,60 \\
4 & 13,00 & 6,00 & 23,00 & $1.794,00$ & $4.843,80$ & 4 & 25,00 & 16,00 \\
5 & 21,00 & 12,00 & 57,00 & $14.364,00$ & $38.782,80$ & 5 & 59,00 & 24,00 \\
6 & 22,00 & 15,00 & 78,00 & $25.740,00$ & $69.498,00$ & 6 & 80,00 & 25,00 \\
7 & 23,00 & 13,00 & 57,00 & $17.043,00$ & $46.016,10$ & 7 & 59,00 & 26,00 \\
8 & 29,00 & 14,00 & 64,00 & $25.984,00$ & $70.156,80$ & 8 & 66,00 & 32,00 \\
9 & 15,00 & 12,00 & 74,00 & $13.320,00$ & $35.964,00$ & 9 & 76,00 & 18,00 \\
10 & 18,00 & 15,00 & 94,00 & $25.380,00$ & $68.526,00$ & 10 & 96,00 & 21,00 \\
\hline
\end{tabular}

C: comprimento da bancada; L: largura da bancada; $\mathrm{H}$ : altura da bancada; V: volume da cama; M: massa da bancada; $\mathrm{Cl}$ : comprimento da cama; LI: largura da cama. 


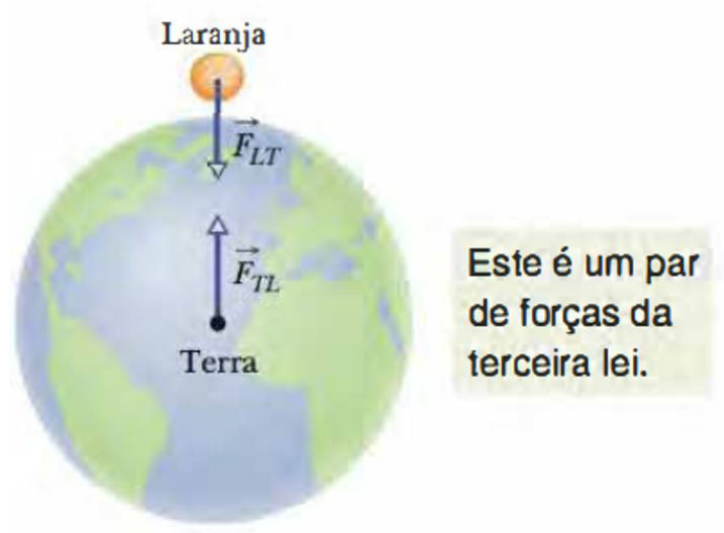

Figura 3. Representação da $3^{\circ}$ lei de Newton que nos mostra que toda ação causa uma reação de igual intensidade, mas com sentido contrário [5].

De posse dos valores da velocidade angular, vamos transformar esse valor em velocidade linear, como será observado na Tabela 3. Para isso, vamos utilizar a Equação 4. O valor do raio de giro será considerado como a altura do centro de massa da bancada em questão.

$$
V_{0}=w \times R
$$

Onde:

$\mathrm{V}_{0}=$ velocidade linear em $\mathrm{m} / \mathrm{s}$;

$\mathrm{W}=$ velocidade angular em rad/s; e

$\mathrm{R}=$ raio de giro em $\mathrm{m}$.

Neste passo, vamos calcular a desaceleração que a cama tem que promover na bancada para que a mesma tenha sua velocidade final igual à zero. Como já temos o valor da velocidade inicial, vamos utilizar a Equação 5 em módulo e obter o valor da desaceleração, na Tabela 4 a seguir.

$$
a=\frac{V 0}{t}
$$

Onde:

$\mathrm{a}=$ desaceleração em $\mathrm{m} / \mathrm{s}^{2}$;

$\mathrm{V}_{0}=$ Velocidade Inicial em $\mathrm{m} / \mathrm{s} ; \mathrm{e}$

$\mathrm{t}=$ tempo em $\mathrm{s}$.

O tempo para efeito de cálculo será considerado

$2 s$, já que todo o processo de tombamento da bancada leva em média 7s.

De posse dos dados encontrados, vamos calcular a massa necessária para a cama de amortecimento realizar uma resposta com mesma intensidade, só que em sentido contrário ao valor da força que a bancada faz sobre ela. Para isso, utilizamos a segunda lei de Newton que é descrita pela Equação 6. Encontramos na Tabela 5 o valor da massa da cama de amortecimento:

$$
M=\frac{F r}{a}
$$

Onde:

$M=$ Massa em $\mathrm{Kg}$;

$\mathrm{Fr}=$ Força resultante em $\mathrm{N}$; e

$\mathrm{a}=$ desaceleração $\mathrm{em} \mathrm{m} / \mathrm{s}^{2}$
Tabela 2. Valores encontrados para força resultante

\begin{tabular}{ccc}
\hline Banca & M (Kg) & \multicolumn{1}{c}{ Fr $(\mathbf{N})$} \\
\hline I & $66.484,80$ & $664.848,00$ \\
2 & $20.250,00$ & $202.500,00$ \\
3 & $10.322,64$ & $103.226,40$ \\
4 & $4.843,80$ & $48.438,00$ \\
5 & $38.782,80$ & $387.828,00$ \\
6 & $69.498,00$ & $694.980,00$ \\
7 & $46.016,10$ & $460.161,00$ \\
8 & $70.156,80$ & $701.568,00$ \\
9 & $35.964,00$ & $359.640,00$ \\
10 & $68.526,00$ & $685.260,00$ \\
\hline
\end{tabular}

Onde as bancadas são as mesmas já utilizadas. A massa será representada por $\mathrm{M}$ e a força será representada por $\mathrm{Fr}$.

Tabela 3. Valores encontrados da velocidade linear

\begin{tabular}{cccc}
\hline Bancada & $\mathbf{R}(\mathbf{m})$ & $\mathbf{W}(\mathbf{r a d} / \mathbf{s})$ & $\mathbf{V}_{\mathbf{0}}(\mathbf{m} / \mathbf{s})$ \\
\hline I & 27,00 & 2,00 & 54,00 \\
2 & 25,00 & 2,33 & 58,33 \\
3 & 13,50 & 3,67 & 49,50 \\
4 & 11,50 & 3,53 & 40,63 \\
5 & 28,50 & 1,67 & 47,50 \\
6 & 39,00 & 1,53 & 59,80 \\
7 & 28,50 & 1,67 & 47,50 \\
8 & 32,00 & 1,60 & 51,20 \\
9 & 37,00 & 2,00 & 74,00 \\
10 & 47,00 & 1,53 & 72,07 \\
\hline
\end{tabular}

Onde temos R como o Raio, Wé a velocidade angular $\mathrm{V}_{0}$ é a velocidade escalar.

\begin{tabular}{|c|c|c|}
\hline Cama & V0 (m/s) & $a\left(m / s^{2}\right)$ \\
\hline I & 54,00 & 27,00 \\
\hline 2 & 58,33 & 29,17 \\
\hline 3 & 49,50 & 24,75 \\
\hline 4 & 40,63 & 20,32 \\
\hline 5 & 47,50 & 23,75 \\
\hline 6 & 59,80 & 29,90 \\
\hline 7 & 47,50 & 23,75 \\
\hline 8 & 51,20 & 25,60 \\
\hline 9 & 74,00 & 37,00 \\
\hline 10 & 72,07 & 36,03 \\
\hline
\end{tabular}

Tabela 4. Valores da desaceleração da bancada quando se encontram com a cama de amortecimento

Onde temos $\mathrm{V}$ como velocidade linear e a como a desaceleração.

Tabela 5. Massa da cama necessária para promover a desaceleração da bancada

\begin{tabular}{cccr}
\hline Cama & Fr $(\mathbf{N})$ & $\mathbf{a ~}\left(\mathbf{m} / \mathbf{s}^{\mathbf{2}}\right)$ & \multicolumn{1}{c}{$\mathbf{M}(\mathbf{k g})$} \\
\hline 1 & $664.848,00$ & 27,00 & $24.624,00$ \\
2 & $202.500,00$ & 29,17 & $6.942,86$ \\
3 & $103.226,40$ & 24,75 & $4.170,76$ \\
4 & $48.438,00$ & 20,32 & $2.384,15$ \\
5 & $387.828,00$ & 23,75 & $16.329,60$ \\
6 & $696.980,00$ & 29,90 & $23.243,48$ \\
7 & $460.161,00$ & 23,75 & $19.375,20$ \\
8 & $701.568,00$ & 25,60 & $27.405,00$ \\
9 & $359.640,00$ & 37,00 & $9.720,00$ \\
10 & $685.260,00$ & 36,03 & $19.017,39$ \\
\hline Onde a Fr é a força resultante, a é a desaceleração e Mé a massa da cama.
\end{tabular}


Tabela 6. Valores utilizados para encontrar a altura da cama de amortecimento hc

\begin{tabular}{crrrrr}
\hline Cama & $\mathbf{M}(\mathbf{k g})$ & $\mathbf{V ~}\left(\mathbf{m}^{3}\right)$ & $\mathbf{C}(\mathbf{m})$ & $\mathbf{L}(\mathbf{m})$ & $\mathbf{h c}(\mathbf{m})$ \\
\hline 1 & $24.624,00$ & $19.699,20$ & 56,00 & 15,00 & 17,16 \\
2 & $6.942,86$ & $5.554,29$ & 60,33 & 13,00 & 11,87 \\
3 & $4.170,76$ & $3.336,61$ & 51,50 & 9,00 & 8,65 \\
4 & $2.384,15$ & $1.907,32$ & 42,63 & 9,00 & 9,54 \\
5 & $16.329,60$ & $13.063,68$ & 49,50 & 15,00 & 18,45 \\
6 & $23.243,48$ & $18.594,78$ & 61,80 & 18,00 & 18,59 \\
7 & $19.375,20$ & $15.500,16$ & 49,50 & 16,00 & 20,21 \\
8 & $27.405,00$ & $21.924,00$ & 53,20 & 17,00 & 20,76 \\
9 & $9.720,00$ & $7.776,00$ & 76,00 & 15,00 & 11,37 \\
10 & $19.017,39$ & $15.213,91$ & 74,07 & 18,00 & 15,09 \\
\hline
\end{tabular}

Onde temos $\mathrm{M}$ como a massa, $\mathrm{V}$ como o volume, $\mathrm{C}$ como o comprimento, $\mathrm{L}$ como a largura e hc é a altura da cama de amortecimento.

Após encontrarmos o valor da massa da cama de amortecimento, vamos considerar que a mesma é composta apenas por argila. Então, vamos dividir pela densidade da argila que é de $1,25 \mathrm{Kg} / \mathrm{m}^{3}$ (informado pela empresa onde foram coletadas as informações). Ao realizar está divisão, se encontra o volume da cama de amortecimento. Como já sabemos o seu comprimento devido a bancada utilizada e a sua largura da mesma forma, pode então fazendo uso da Equação 2, para encontrar a altura teórica da cama, na Tabela 6.

\section{CONCLUSÕES}

Observamos que os modelos empíricos de confecção de cama de amortecimento para rocha ornamental, não são suficientes para prover o bom amortecimento das bancadas, impedindo que estás quando tenham alturas superiores a $50,00 \mathrm{~m}$ venham a quebrar em contato com a cama.

Com este estudo, foi possível criar um modelo de dimensionamento, no qual vamos garantir que a bancada ao entrar em contato com a cama de amortecimento não se quebres sendo possível com isso, melhorar a recuperação da bancada e o aproveitamento de alguns blocos.

Devido ao grande volume de material terroso movimentado, esperamos que a confecção da cama de amortecimento eleve os custos do empreendimento, mas este novo processo diminui as micro trincas causadas pela queda da bancada, podendo assim melhor o desempenho na etapa posterior de beneficiamento, apesar deste ganho é necessário se pensar em novas tecnologias mais econômicas e viáveis para o processo de amortecimento das bancadas de rocha ornamental.

\section{REFERÊNCIAS}

I Associação Brasileira da Indústria de Rochas Ornamentais [página de internet]. Brasília: ABIROCHAS; 2017 [acessado em 10 jan. 2018]. Disponível em: http://www.abirochas.com.br/Exp-imp-out-2017.pdf

2 Silva RF, Rocha SS, Araújo ACV, Barros MLSC, Assis MS. Padronização da metodologia de ruptura basal em cunha, para tombamento de painéis verticais na lavra de rocha ornamental. Tecnologia em Metalurgia, Materiais e Mineração. 2019;16(I):57-6I.

3 Almeida FFM, Hasui Y, Neves BBB, Fuck RA. Províncias estruturais brasileiras. In: Anais do Simpósio de Geologia do Nordeste; 1977; Campina Grande. Campina Grande: SBG; 1977. p. 363-39I.

4 Sardou FR. Atlas de rochas ornamentais do estado do Espirito Santo. Brasília: CPRM; 2013.

5 Halliday D, Resnick R, Walker J. Fundamentos de física. Rio de Janeiro: Livros Técnicos Científicos; 20I2. (Vol. I).

Recebido em: 29 Jan. 2019

Aceito em: 18 Set. 2019 